\title{
Comparative study of the efficacy of nanocrystalline silver dressing and silver sulfadiazine applied on burns in hospitalized patients
}

\author{
M. N. Silva ${ }^{1}$, M. Taminato ${ }^{2}$, A. L. R. Z. Beretta ${ }^{1}$ \\ ${ }^{I}$ Graduate Program in Biomedical Sciences. University Center Hermínio Ometto- UNIARARAS/ Araras, SP, \\ Brazil. Microbiological Research Laboratory. \\ ${ }^{2}$ University Federal de São Paulo - UNIFESP/SP, Brazil.
}

\begin{abstract}
Objective: To evaluate the efficacy of dressing based on silver as nanocrystalline silver and silver sulfadiazine in patients with burns and clinical signs of infection, in the healing process, seeking a favorable outcome of local therapy. Methods: A prospective and exploratory study, carried out with patients with burns with a quantitative approach by the method of clinical investigation. The study population comprised 30 patients, burn victims, aged between 03 and 40 years old. The patients had between 04\% to 27\% of Body Surface Burned ( $S C Q$ ), with the majority of second degree burns. Topical therapy was performed in 30 patients with exudating wounds, while 15 patients received injections of silver sulfadiazine and 15 nanocrystalline silver. Results: Patients who used nanocrystalline silver showed significant improvement of the lesions in addition to decreased exudation and early epitheliazation after the second day of healing, while those who had used silver sulfadiazine began to show improvement from the fourth day of healing. Conclusions: The results with nanocrystalline silver showed a reduced incidence of exudate in comparison with the dressing made with silver sulfadiazine.
\end{abstract}

Keywords: Burns, Silver, Therapeutic use, Dressings.

\section{INTRODUCTION}

Burns are complex injuries with litigation scar, that dispute the interface of care in various segments and promote the status of a hard and sorrowful process of coping by patients and the multidisciplinary team [1].

Burn patients have systemic inflammatory reaction that modifies the metabolism and may make infection of the burned area. Two factors contribute to the increase of incidence of infection: the loss of continuity and immunosuppression resulting from the burn itself. In the case of patients with medium and large burns, the several organic changes caused interfere and make the treatment more difficult [2].

The burn patients represent a population highly susceptible to infection by microorganisms of endogenous and exogenous origin, as a result of disruption of the normal skin barrier, followed by depression of the immune response [3]. Initially the lesioned skin is considered free of bacteria, killed by heat. However, the large amount of necrotic tissue, exudates rich in protein, and the drop in the oxygen supply provides an excellent mean for the development and proliferation of microorganisms [4].

The systemic antibiotic therapy, most often becomes inefficient due to the interruption of local blood flow. Therefore, the success of the therapy and perhaps the greatest challenge to care for burn patients is to control infection and prevent a possible septicemia, since many of these infections can be caused by multidrugresistant strains [5].

There is a great need to standard practices related to the treatment of wounds, especially in terms of procedures with dressings. The development of new products and techniques to perform curative and adjuvant methods in wound care has required the creation of study groups on the skin lesions. Although it is believed that the resources and existing technologies can be sufficient, much remains to be further investigated in this field, to promote an improvement of such resources and development of effective technologies and thus make them accessible to as many people as possible $[6,7,8]$.

In this sense, care for wounds, stimulated by the continuous improvement of Technologies and innovate practices are causing numerous questions regarding the efficacy of products used to treat, since the incidence and prevalence of skin lesions are still extremely high, resulting in high financial costs and social consequences to the carriers, who often develop sequelae that lead to abscence from work and normal activities [9].

Besides the immediate repercussions consequent to burns, physical and emotional sequelae of the burn patient and his family remain for life. Recent advances in our understanding of the pathophysiology of the metabolic response to burns, wounds care, new surgical techniques and bioengineered skin have shown excellent results in most patients who survive burn trauma $[10,11,3]$. 
The injury caused by the burning can be described based on its depth, being classified as first degree, when committed only the epidermis, showing erythema and pain, second degree, when it reaches the dermis and epidermis, causing the formation of flictemas, and third degree, when it involves all structures of the skin, appearing white or black, slightly painful and dry. In the choice of treatment, one must consider not only the depth of the injury, but also the development phase [4].

Burns of second and third degree must go through a process of debridement that consists in the removal of devitalized tissues, which may take longer and require more intervention, depending on the depth and extent of the burn [12].

Most often it is difficult to determine the presence and degree of infection in burn injury, which remains the leading cause of death, estimated in $75 \%$ of the deaths in patients who survive the initial period of shock are related to invasive infection $[13,5]$.

Various types of dressings have been developed for application to burns, but studies show that the use of silver-based dressings is effective in the prevention and treatment of contaminated areas Campos et al. [5] show that the nanocrystalline silver has homogeneous release and maintenance of their own environment for reepithelization. Since ancient times, silver is used for medicinal purposes since the Greeks and Native Americans have used silver for desinfection [14].

In the beginning of the century, there are still many controversies about the best therapy for the topical treatment of wounds. It is understood by the topical set of behaviors aimed at early healing of wounds and includes cleansing, debridement and coverage [14].

The experience accumulated over the past three decades, early intervention in the treatment of burn patients has changed dramatically the cause of death, it is now estimated that about $75 \%$ mortality after burns is related to infection rather than osmotic shock and hypovolemia. Therefore, knowledge of the flora of bacteria responsible for burns, its prevalence and antimicrobial resistance is crucial for rapid and reliable therapeutic decisions [15].

One of the successes of topical formulations is that they have lower toxicity and greater local action. In the last two decades with the advent and development of nanotechnology, new formulations of silver appear as the therapeutic option $[8,9,16]$.

Silver compounds have been exploited for their medicinal properties for centuries. Currently, silver is re-emerging as a viable treatment option for infections encountered in burns, open wounds and chronic ulcers. The gold standard for the topical treatment of burns is silver sulfadiazine, an antibacterial agent useful for the treatment of burns. Recent discoveries, however, indicate that the compound retards the wound healing process and that the silver may have severe cytotoxic activity in different host cells [17].

The cover with nanocrystalline silver is a technology that is labeled to prevent and treat infections in burns and other types of acute and chronic wounds. Composed of polyester and rayon, silver is impregnated with nanocrystalline silver small crystalls (nanocrystals) and acts as an antimicrobial barrier that acts on superficial and deep wounds, releasing silver ions more rapidly that the common silver, and therefore protects injured in particular burns, microbial colonization and possible infection, and treats them when this complication is already installed [18].

The importance of studying permeates into the challenge, especially access to different behaviors of treatment, it is apparent that health professionals involved in treatment, have been following the developments in this area, expanding new concepts and alternative technologies, as well as developing standards and ever more efficient routines for skin care and wounds, trying to adapt them to better clinical practices and the various care settings.

Given the above, the study describes the favorable local therapy in patients with silver average burned in the healing process. This was a comparative method of local therapy with nanocrystalline silver and silver sulfadiazine in burn patients.

\section{II. casuistry and methods}

The study was conducted after approval by the Ethics Committee under protocol 190/10. The sample was composed of children and young adult patients of both sexes admitted to the Burn Care Unit of a hospital in São Paulo.

It was a study with a quantitative approach using the method of clinical research and comparative. The groups were then compared with respect to the evolution of wound healing time and need for surgery to close wounds. Continuous data were analyzed using tests of mean, standard deviation and coefficient of variation.

The study population consisted of 30 patients, including children and Young adults admitted to the Unit of Treatment of Burns and patients with burns of second and third degree in treatment during the period of March 2011 to July 2011 and who used local coverage nanocrystalline silver or silver sulfadiazine: 15 patients in the control group using silver sulfadiazine who received daily changes of dressings and 15 patients using nanocrystalline silver that received changes every 72 hours. 
Analysis of the effects of the treatments was carried out using a photographic record in a distance of 30 $\mathrm{cm}$. with digital camera with 14.1 megapixels and the images were projected for the three-dimensional modeling tool (SketchUp).

Fifteen consecutive patients with burns of medium size (less than 30\% SCQ) were treated with nanocrystalline silver. The patients were requested when required and burn dressings were coated with the nanocrystalline silver base within the anatomical possibility. Anesthesia or deep sedation was provided by the department of anestesia when needed, before the beggining of dressing changes, and the patients remained in the operating room of the burns unit for recovery after sedation. The debridement and skin grafts were determined as required for areas that do not burn properly heal.

Data were collected prospectively for these patients, including percentage of body surface burned (SCQ) and percentage of total depth (PTP). The percentage of SCQ and PTP was estimated by the physician at the time of admission, and PTP was confirmed at the time of surgery. These data were collected prospectively from March 2011 to July 2011 and compiled in the database of Lund-Browder burns.

\section{Results}

Demographic data of 15 patients in the nanocrystalline silver and 15 control patients in the control group of silver sulfadiazime show that the mean age of patients treated with nanocrystalline silver is 14 years old and the group of silver sulfadiazime is $8 \%$. The mean percentage of total depth burned both the nanocrystalline silver group as the group of silver sulfadiazime was $2.2 \%$.

The duration of stay in the burns unit was statistically different between groups. The nanocrystalline silver group had an average of 4.5 days of hospitalization while patients treated with silver sulfadiazine had an average of 8.2 days.

Five patients $(33 \%)$ treated with nanocrystalline silver needed debridement of the burned area and thrre $(20 \%)$ required debridement and skin grafting, compared with 15 patients $(50 \%)$ who were treated with silver sulfadiazine. One patient $(6.6 \%)$ in the group of nanocrystalline silver, which took two debridement procedures, while there were six $(40 \%)$ in the silver sulfadiazine group who required two procedures. The average number of procedures performed in patients treated with silver sulfadiazine was $100 \%$ and those treated with nanocrystalline silver had a percentle of $33.3 \%$.

From the 30 recruited patients (17 men and 13 women), there was a mean age of 14.93 (range $3-40$ years old) and a mean of SCQ of $19.3 \%$ (range, 4-27\%).

Of the 15 lesions treated with nanocrystalline silver, 9 were in the upper extremities, 3 in the lower and 3 in the torso. Of the fifteen lesions treated with silver sulfadiazine, 8 were in the upper ends, 5 were the lower extremities and 2 were in the trunk, 13 lesions were caused by flames, 15 by scald and 2 by electricity.

The results indicate that the burn from scalding was higher in the group treated with nanocrystalline silver (Figure 1), whereas in the group of silver sulfadiazine burning flame led (Figure 2). The burning for electricity had a low percentile of $6.6 \%$ and this event occured only in the group of silver sulfadiazine.

It was observed by means of projected images for three dimensional modeling (SketchUp) that patients who used silver nanocrystalline showed improvement of injuries, in addition to decreased exudation and early epithelialization after the second day of healing, while those who did use silver sulfadiazine began to show improvement from the fourth day of healing.

Using the data on which the percentages of SCQ where scald burns were treated with nanocrystalline silver-based dressings, one obtains an average $8.15 \%$, standard deviation $5.88 \%$ and coefficient of variation $72.15 \%$. The same procedure for the data where the percentage of SCQ burns from scald was treated with silver sulfadiazine-based dressings, one obtains an average $10.20 \%$, standard deviation $4.82 \%$ and coefficient of variation $47.16 \%$.

Using the data on the SCQ percentages where the flame burns were treated with nanocrystalline silverbased dressings, one obtains an average $12.80 \%$, standard deviation $9.11 \%$ and coefficient of variation $71.17 \%$. The same procedure for data regarding the percentage of SCQ where the flame burns were treated with silver sulfadiazine-based dressings, one obtains an average $6.88 \%$, standard deviation $3.29 \%$ and coefficient of variation $47.82 \%$.

The comparative sutdy between the recruited patients shows that the ones who used silver sulfadiazine were longer hospitalized (avarage of four days or longer) compared to patients who were treated with nanocrystalline silver. This study suggests that nanocrystalline silver when deposited in a humid environment of the wound increases the rate of epithelialization compared with silver sulfadiazine.

The results demonstrate a reduction in burn wound exudate after treatment with nanocrystalline silver, characterizing in greater epithelialization of the wound bed. 


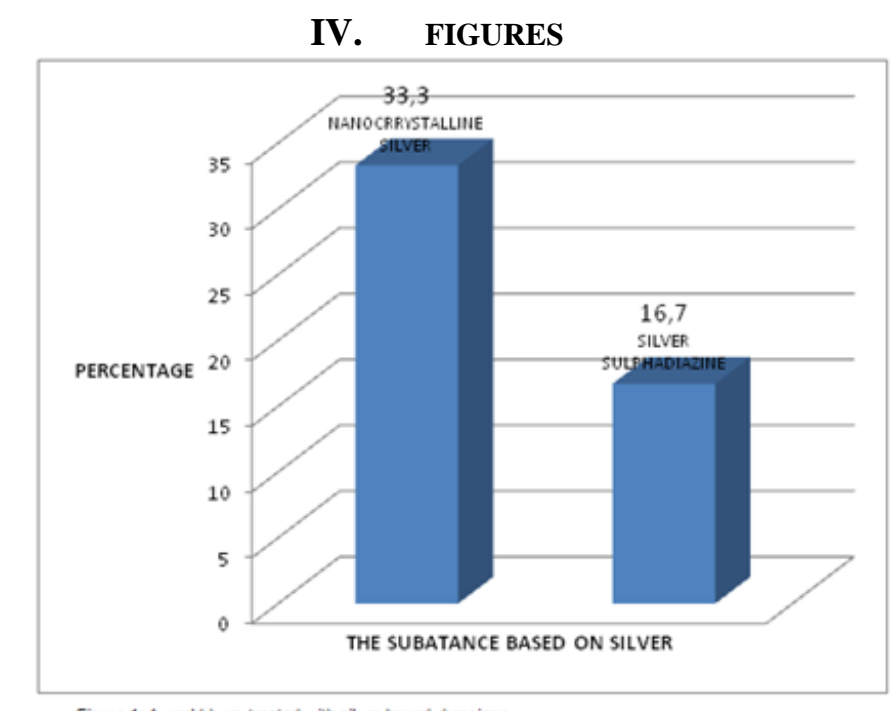

Figure 1: A scald burn reated with silver.based dessings

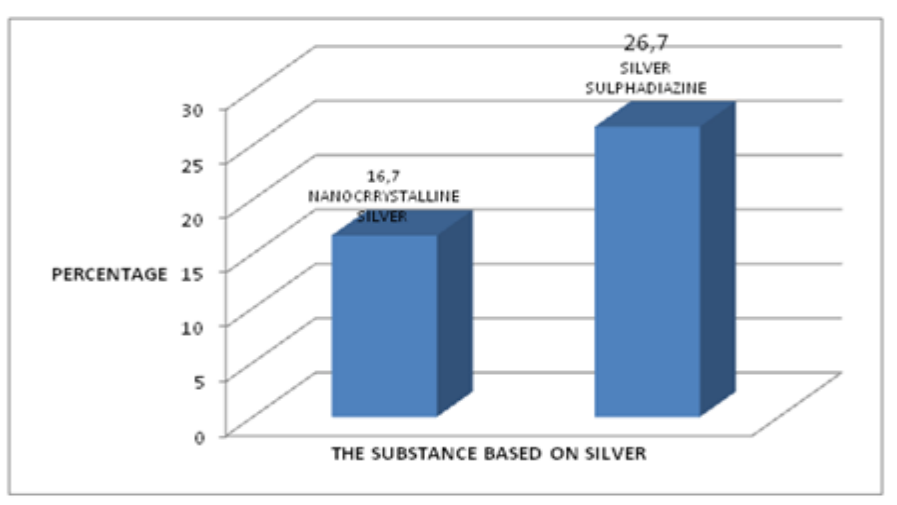

Figure 2: Flame bum reated with silver-based dressings

\section{CONCLUSION}

Considering that the coefficient of variation $72.15 \%$ and $71.17 \%$ are very close, we can conclude that the effectiveness in improving the substance provided by nanocrystalline silver is roughly equivalent regardless to etiology (burns from scald or flame), the same conclusion applies to the substance silver sulfadiazine $(47.16 \%$ coefficient of variation for burns from scalding and $47.82 \%$ coefficient of variation for flame burn).

Since the treatment of scald burns nanocrystalline silver-based prevents both a standard deviation as a coefficient of variation that is greater than the treatment of scald burns silver sulfadiazine-based, it is concluded that the nanocrystalline silver shows to be more effective in improving the largest amplitude for a percentage of body surfaces burn victims, id est, Since the treatment of scald burns nanocrystalline silver-based presents both a standard deviation as a coefficient of variation that is greater than the treatment of scald burns based on silver sulfadiazine, it is concluded that the nanocrystalline silver shows to be more effective in improving the largest amplitude for a percentage of body surfaces burn victims, id est, the time interval (dispersion) of action of the substance is nanocrystalline silver broader compared to the range of action of the substance silver sulfadiazine .

For the treatment of burning flame nanocrystalline silver-based which has both a standard deviation and coefficient of variation greater than compared to the flame burning treatment based on silver sulfadiazine, it is concluded that also for this case the nanocrystalline silver showed to be more effective in improving the framework for a greater range of percentages of body surfaces that suffer burns, id est, the range (dispersion) of action of nanocrystalline silver substance that is wider compared to the range of action of the substance silver sulfadiazine.

This study investigated the topical treatment of nanocrystalline silver and silver sulfadiazine by the comparative method, and no specific report was obtained with respect to the cost of treatment, but, according to Sheridan et al. [16] and Peters \& Verchere [2] by reducing the number of dressing changes, significant savings in materials and labor can be achieved. Peters \& Verchere [2] demonstrate in their study that the institution where the research was developed there was a reduction of days of stay in the hospital where the patients were topical treated with nanocrystalline silver. They also state that the number of surgical desbridations and procedures of skin grafting was higher in the group treated with silver sulfadiazine. 
The findings of this study indicate that coatings containing nanocrystalline silver are an excellent choice to combat microbial topic oozing wounds that present in abundance.

\section{Acknowledgements}

We thank FAPESP for financial support. Source of funding: FAPESP

\section{REFERENCES}

[1]. V.D.S. Carlucci, L.A. Rossi, A.M.F.T. Ficher, E. Ferreira, E.C. Carvalho, Burn experiences from the patient's perpective. Rev.esc.Enf.USP. 2007; 41(1):21-8.

[2]. D.A. Peters, C. Verchere, Healing at home: comparing chorts of children with médium-sized Burns treated as outpatients with inhospital applied Acticoat ${ }^{\mathrm{TM}}$ to those children treated as inpatients with silver sulfadiazine. J.Burn Care Res.2006;27:198-201.

[3]. M.A. Cyrillo, Microrganismos, Microbiologia e suas aplicações. Prática Hospitalar, São Paulo. 2000; $8: 41-43$

[4]. S. Erol et al. Changes of microbial flora and wound colonization in burned patients. Burns. 2004; 30: 357-61.

[5]. R. Strohal, M. Shelling, M.. Takacs, W. Jurecka, U. Gruber, F.Offner, Nanocrystalline silver dressing as na efficient anti-MRSA barrier: a new solution to na increasing problem.J.Hosp.Infec. 2005;60(3): 226-30.

[6]. Mandelbaum SH, Di Santis EP, Mandelbaum MHS. Cicatrização: conceitos atuais e recursos auxiliares. Anais Brasileiros de Dermatologia 2003;78(5):525-542.

[7]. A.C. Oliveira, Infecções Hospitalares: Epidemiologia, Prevenção Controle. Guanabara Koogan ,Rio de Janeiro, 2005.

[8]. A.AC. Campos, Protocolo de cuidados de feridas. 2008 - [ cited 2012 jan 8]. Available from: http://www.pmf.sc.org.br

[9]. D.L.P. Campos, L.V. Fragadolli, G.A. Gimenes, O.O. Ruiz, F.S. Orgaes, H.A. Gonella, Uso de curativo com prata nanocristalina sobre enxerto em malha em queimaduras colonizadas por cepas multirresistentes. Revista Brasileira de Cirurgia Plástica,2009; 24(4):471-478

[10]. F.S.L. Gomes, Tratamento de feridas crônicas com cobertura oclusivas: alteração qualitativa da microbiota. Dissertação de mestrado, Universidade Federal de Minas Gerais: UFMG, 2001,150p.

[11]. G. Iron, Feridas: novas abordagens, manejo clínico e atlas em cores, Guanabara Koogan, Rio de Janeiro, 2005.

[12]. R.S. Ward, J.R. Saflle, Topical agents in burn and wound care. Phys Ther.2005; 75(6): 526-38.

[13]. H. Vindenes, R. Bjerknes, Microbial colonization of large wounds. Burns.1995;21 (8):575-579.

[14]. A.S. Jorge, S.R.P.E. Dantas, Abordagem multiprofissional do Tratamento de feridas, Atheneu, São Paulo, 2003.

[15]. J.L.S. Macedo, J.B. Santos, Bacterial and fungal colonization of burn wounds. Mem Inst Oswaldo Cruz. 2005; 5:535-539.

[16]. V. Declair, S.M.C. Pinheiro, Novas considerações no tratamento de feridas. Revista Paulista de Enfermagem. 1998; 17:25-38

[17]. [17] B.S. Atiyeh, M. Costagliola, S.N. Hayek, S.A. Dibo, Effect of silver on burn wound infection control and healing: Review of the literature. Burns, 2007; 3 3:1 $139-148$

[18]. Portugal C, Garrido D, Coutinho M 2010. Eficácia na cicatrização em queimadura utilizando prata nanocristalina: estudo de caso: Disponivel em :http://www.sobest.com.br/index.php?option=com content\&task=view\&id=203 Acesso em $28 \mathrm{dez} 2010$.

[19]. R. Sheridan, L. Petera, M. Lydon, F. Salvo, Once-daily wound cleansing and dressing chance: efficacy and cost. J.Burn Care Rehabil. 1997; 18:139-40. 